\title{
Prevalence and genotype distribution of human papilloma virus in cervical samples of young married women: a hospital based prospective cross-sectional study
}

\author{
Madhuri N. Bagde ${ }^{*}$, Nilajkumar D. Bagde², Pooja Deshmukh ${ }^{3}$, \\ Sanjay Negi ${ }^{4}$, Pugazhentan Thangaraju ${ }^{5}$
}

\begin{abstract}
${ }^{1}$ Department of Obstetrics and Gynecology, Raipur Institute of Medical Sciences, Raipur, Chhattishgarh, India ${ }^{2}$ Department of Obstetrics and Gynecology, ${ }^{4}$ Department of Pharmacology, ${ }^{5}$ Department of Microbiology, ${ }^{2,3,4,5} \mathrm{All}$ India Institute of Medical Sciences, Raipur, Chhattisgarh, India
\end{abstract}

Received: 25 September 2021

Accepted: 16 October 2021

\author{
*Correspondence: \\ Dr. Madhuri N. Bagde, \\ E-mail: madhuririmsraipur@gmail.com
}

Copyright: ( ) the author(s), publisher and licensee Medip Academy. This is an open-access article distributed under the terms of the Creative Commons Attribution Non-Commercial License, which permits unrestricted non-commercial use, distribution, and reproduction in any medium, provided the original work is properly cited.

\section{ABSTRACT}

Background: The aim of the study was to determine the prevalence and genotypes of human papillomavirus (HPV) infection in the cervical samples of young married women at a tertiary care hospital in Chhattisgarh. A prospective cross-sectional observational study was performed in married women, aged 18 to 30 years.

Methods: Relevant history was noted and cervical samples were collected and tested for HPV deoxyribonucleic acid (DNA) by polymerase chain reaction (PCR). Data was compiled to calculate the prevalence of HPV and the genotypic distribution.

Results: The overall prevalence of HPV in this study was $22.73 \%$ and that of type 16 and 18 either alone or in combination with other subtypes was $17.26 \%$. They were the commonest subtypes. HPV positivity was inversely related to education levels (Chi square, $\mathrm{p}=0.05$ ). There was a significant difference in parity of women testing positive for HPV versus those negative for HPV (one tailed $\operatorname{Pr}(\mathrm{t}<\mathrm{t})=0.03,95 \% \mathrm{CI}=1.445$ to 1,865 at 108 degrees of freedom). No difference was observed between education and socio economic levels of positive versus negative women. Type 16 and 18 accounted for $76 \%$ of all HPV subtypes detected.

Conclusions: The prevalence of HPV infection is high in Indian women. The high risk oncogenic types are the commonest subtypes. There is an urgent need to screen for the presence of high risk HPV infections in younger women so that they may be followed up more closely to prevent cervical cancers.

Keywords: Human papilloma virus, Cervical cancer, Screening, Prevalence, Genotype-DNA PCR

\section{INTRODUCTION}

Cervical cancer affects approximately 1 in 53 Indian women during their lifetime. ${ }^{1}$ According to the human papilloma virus (HPV) and related cancers in India summary report 2010, it is estimated that every year 1, 34, 420 women are diagnosed with cervical cancer and 72,825 die from this disease. ${ }^{2}$ Most cases of cervical intraepithelial neoplasia and cancer are attributed to infections with one or more of the 15 oncogenic or high risk types of HPV. 3,4 More than 100 types of papilloma viruses have been identified, of which 40 are known to affect the genital tract. About $3-10 \%$ of women who are unable to clear the infection become persistent carriers. ${ }^{5}$ The commonest high risk HPV subtypes in decreasing order of prevalence are $16,18,58,33,45,31,52,35,59,39,51$ and 56. Type 16 and 18 account for $70 \%$ of all cervical cancers. ${ }^{6}$ Co infection with multiple HPV genotypes may interact or act in synergism and lead to progression of the disease. ${ }^{7}$ Chhattisgarh is a tribal area. A study to detect HPV prevalence in tribal women of Chhattisgarh (a state in 
India) using self-collected urine samples reports $12.2 \%$ prevalence of $\mathrm{HPV}{ }^{8}$

Insufficient data is available regarding HPV infection in this tribal belt. The present study aims to find out the prevalence and genotype distribution of cervical HPV infection in young married women attending the outpatient department of obstetrics and gynaecology (GOPD) at All India Institute of Medical Sciences (AIIMS), Raipur so as to gain insights regarding gravity of the issue and pave way for future research and interventions in this direction.

\section{METHODS}

\section{Study design}

A prospective cross sectional observational study at a tertiary care institute, in the GOPD, AIIMS, Raipur. The study was conducted after due approval from the ethical committee of AIIMS Raipur.

\section{Study population}

The eligibility criteria were married women aged 18-30 years attending the GOPD. Universal sampling technique was used and all women fulfilling the eligibility criteria for the duration of the study were approached for enrollment. Women were enrolled for screening irrespective of their complaints.

\section{Exclusion criteria}

Unmarried women, pregnant women or those having undergone electrocoagulation, cryotherapy, or conization for cervical disease in the past 6 months were not eligible.

\section{Data collection}

Patients were provided with detailed information about the procedure and a written informed voluntary consent to use the data for research purpose and publishing was obtained, in their local language. Patient confidentiality was maintained and a relevant clinical history regarding presenting complaints, menstrual history, obstetric history, was noted. The education level was recorded as the highest class that was successfully cleared by the person with a pass grade. Cervical samples for HPV were collected using a cyto brush and sent for lab testing. Lab results were collected for HPV positivity and genotypes. HPV genotypes were detected in the clinical specimen of cervical scrape by following the procedure mentioned as under.

\section{HPV DNA extraction}

The cervical specimen was centrifuged at $13000 \mathrm{rpm}$ for 1 min to obtain the pellet that was washed in $500 \mu \mathrm{l}$ PBS solution. This suspension was again centrifuged at 13000 rpm for $1 \mathrm{~min}$. The supernatant was discarded and the pellet was processed for DNA isolation using commercially available DNA extraction kit (QIAmp DNA mini kit, QIAGEN, Hilden, Germany) as per the manufacturer's instruction. Purity and concentration of DNA was checked by determining A260 and A280 using Qubit 4 fluorometer (Thermo Fisher Scientific, USA). Sample yielding DNA concentration $\geq 50 \mathrm{ng} / \mu \mathrm{l}$ was processed further.

\section{HPV genotyping}

HPV genotyping analysis was performed using Anyplex ${ }^{\mathrm{TM}}$ 14 HR-HPV detection assay (Seegene, Seoul, Korea) according to manufacturer's instruction using a CFX 96 real time thermocycler (BioRad, Hercules, California). It is based on the TOCE (tagging oligonucleotide cleavage and extension) technology which is initiated with hybridization of the dual priming oligonucleotide primers and the "pitcher" to the target HPV sequence. Taq polymerase with 5 '-nucelase activity encounters the target bound pitcher and releases the tagging portion of the pitcher. The sequence of the released tagging portion is complementary to the capturing portion of the "catcher" as an artificial template. As the tagging portion is fully extended on the "catcher" to create the "duplex catcher" quenching is diminished and the fluorescent signal can be detected. Approximate time from processing of clinical sample to DNA extraction and real time PCR amplification with melting analysis was around 5 hour. Briefly PCR reaction performed in a $20 \mu \mathrm{l}$ reaction consisting of $5 \mu \mathrm{l}$ extracted DNA, 4X HPV HR TOCE oligo mix, and Anyplex PCR mix containing uracil DNA glycosylase. The thermal cycling parameter included initial incubation at $50{ }^{0} \mathrm{C}$ for 4 minute for activation of the uracil DNA glycosylase system to prevent contamination, denaturation at $95{ }^{0} \mathrm{C}$ for 15 minutes, followed by 50 cycles of denaturation $\left(30\right.$ seconds at $95{ }^{\circ} \mathrm{C}$ ), annealing $(1 \mathrm{~min}$ at 60 ${ }^{0} \mathrm{C}$ ) and elongation (30 seconds at $\left.72{ }^{\circ} \mathrm{C}\right)$. Cyclic catcher melting temperature curve analysis was performed after PCR cycles 30,40 and 50 by cooling of the reaction mixture to $55^{0} \mathrm{C}$, holding at $55^{\circ} \mathrm{C}$ for 30 seconds and heating from $55{ }^{0} \mathrm{C}$ to $85{ }^{\circ} \mathrm{C}\left(5 \mathrm{~s} / 0.5{ }^{\circ} \mathrm{C}\right)$. The $\mathrm{L} 1$ gene of HPV DNA and the human housekeeping gene (human $\beta$ globin) were co-amplified simultaneously, and the human housekeeping gene was used as an internal control to monitor DNA purification efficiency, PCR inhibition and cell adequacy. DNA interpretation was done with the Anyplex software (Seegene) according to the manufacturer's instructions.

\section{Statistical analysis}

Data entry and cleaning was done using STATA and the output was analyzed and presented as tables and graphs. Age was analyzed as a continuous as well as categorical variable. The subcategories were defined as women less than 25 years and those 25 years and above. Education was divided into the following categories: illiterate, primary education till standard 4 (primary), secondary education till standard 10 (secondary), higher secondary education till standard 12 (higher secondary), graduate educated till 
$12+3$ years bachelor degree (graduate), post graduate or professional course educated till $12+5$ years or holding a professional degree e.g. medicine, engineering, chartered accountant (post graduate). Categories were further clubbed into different combinations for analysis. Occupation was categorized as housewife (meaning not employed for earning income), unskilled worker (included laborer and house maids), skilled worker (included those employed in artisan crafts like tailoring, office assistant) and professional job (nursing, engineering). Modified Kuppuswamy scale was used to define the socio economic strata. The categories were upper class, upper middle class, middle class, lower middle class and lower class in that order.

Independent group $\mathrm{t}$ test was used to compare means of continuous variables at an alpha level of 0.05 for significance. If significance was observed alone at a one or two tailed level it was specified. Categorical data was analyzed by Chi square test $\left(\chi^{2}\right)$ at alpha level of 0.05 . Simple logistic regression was used to test effect of continuous variables on HPV status. Wilcoxin rank sum test (Mann-Whitney) was used to compare underlying differences for ordinal data like the socio-economic status.

\section{RESULTS}

\section{Age, parity and $\mathrm{HPV}$}

During the study, 134 women fitted the eligibility criteria of which 110 gave consent for study. The age ranged between 18 to 30 years. Of these $79 \%$ were aged 25 years or more. Of the total 110 women, $22.73 \%$ tested positive for one or more type of HPV infection. Of these positive women, $76 \%$ were aged 25 years or more. Of the total 110 women, $19 \%$ women less than 25 years of age and $24.05 \%$ women aged equal to or more than 25 years tested positive for HPV. A model designed using age as a continuous variable to compare its relation with HPV status did not reach statistical significance (logistic regression $\chi^{2}$, $\mathrm{p}=0.21)$. There was no statistical difference in HPV status and age $<25$ years compared to $\geq 25$ years $\left(\chi^{2}, p=0.597\right)$ (Table 1).

The mean parity of the study population was $1.64 \pm 1.1$, of HPV negative women was $1.75 \pm 1.1$ and of women positive for HPV was $1.28 \pm 1.1$. Parity was significantly different in women positive with HPV compared to those that tested negative (One tailed $\operatorname{Pr}(\mathrm{T}<\mathrm{t})=0.03$, 95\% CI 1.445 to 1.865 , at 108 degrees of freedom).

\section{Education and HPV}

$13.64 \%$ women were illiterate, and $7.27 \%$ held a post graduate or higher degree. Most of the women (44.54\%) had received education either till secondary or higher secondary level. On comparing level of education and HPV positivity, HPV was encountered significantly more frequently in women having lower levels of education $\left(\chi^{2}\right.$, $\mathrm{p}=0.05$, Fisher's exact 0.03 ). A prediction model for effect of education on HPV positivity demonstrated an overall significant difference among categories (logistic regression $\chi^{2}=11.92, \mathrm{p}=0.03$ ). There was a positive correlation with HPV status and education till secondary school which changed to a negative one with higher educational strata though none reached statistical significance at individual level (Table 2).

\section{Occupation, socio economic class and HPV}

HPV positivity did not differ in relation to the occupation of patients $\left(\chi^{2}=0.97, p=0.80\right)$. No difference was observed in the socio economic patterns of women with relation to their HPV status (Mann-Whitney, $\mathrm{z}=-1.282, \mathrm{p}=0.19$ ) (Table 1 and Figure 1).

\section{Type of HPV}

The overall prevalence of HPV infection was 22.73 (95\% CI 14.90 to 30.56 ) in the study population. The commonest subtype was type 16 followed by type 18 (Table 2). More than one subtype was positive in $4.54 \%$ of all women. Amongst those positive for HPV, type 16 accounted for $60 \%$ either alone or in combination with other serotypes (type 18, 31, 33, 39 or 52) (Figure 2). Type 18 was the second commonest, found alone in $12 \%$ and in combination with type 16 in $16 \%$. Type 31 was found in combination with type 16 or 52 in $8 \%$ women. Type 33 was found in $8 \%$ alone and $12 \%$ either alone or in combination with type 16 . Type 39 was found in combination with type 16 or alone in $8 \%$ women. Type 52 was found alone or in combination with type 31 in $8 \%$ women. Type 56 and 66 were found alone in 4\%. Amongst those positive for HPV, $20 \%$ had more than one subtype (Table 4 and Figure 2).

Table 1: Age, parity, socio economic distribution and HPV status.

\begin{tabular}{|llll|}
\hline Parameters & All women & HPV negative women & HPV positive women \\
\hline Age (mean+standard deviation) years & $27.07+2.68$ & $26.90+2.71$ & $27.64+2.53$ \\
\hline Parity (mean+standard deviation) & $1.64+1.16$ & $1.75+1.16$ & $1.28+1.1$ \\
\hline Socio economic status level: $\mathbf{1}$ & $\mathrm{N}=15$ & $93.33 \%$ & $6.67 \%$ \\
\hline Socio economic status level: $\mathbf{2}$ & $\mathrm{N}=11$ & $90.91 \%$ & $9.09 \%$ \\
\hline Socio economic status level: $\mathbf{3}$ & $\mathrm{N}=45$ & $68.89 \%$ & $31.11 \%$ \\
\hline Socio economic status level: $\mathbf{4}$ & $\mathrm{N}=23$ & $82.61 \%$ & $17.39 \%$ \\
\hline Socio economic status level: $\mathbf{5}$ & $\mathrm{N}=16$ & $68.75 \%$ & $31.25 \%$ \\
\hline
\end{tabular}


Table 2: Correlation of HPV with education level.

\begin{tabular}{|lll|}
\hline Parameters & \multicolumn{1}{l}{$\begin{array}{l}\text { Logistic regression Chi } \\
\text { square probability }\end{array}$} & $\begin{array}{l}\text { 95\% confidence } \\
\text { interval }\end{array}$ \\
\hline Difference across all categories: overall predictor model & 0.03 & -1.788 to 0.109 \\
\hline $\begin{array}{l}\text { Education till middle school versus secondary or higher } \\
\text { Education (illiterate, primary and post graduate versus } \\
\text { middle, secondary and higher education) }\end{array}$ & 0.087 & -1.708 to 0.117 \\
\hline $\begin{array}{l}\text { Education (illiterate, primary, middle school and post } \\
\text { graduate versus high school and graduate) }\end{array}$ & 0.089 & -3.059 to -0.500 \\
\hline
\end{tabular}

Table 3: Clinical complaints and HPV positive status.

\begin{tabular}{|llll|}
\hline Complaint & Total women with complaint* & HPV status & \% HPV positive \\
\hline Swelling over genitalia & 4 & 100 & 0 \\
\hline Burning in micturition & 14 & 78.57 & 21.43 \\
\hline White discharge & 54 & 75.93 & 24.07 \\
\hline Pain in abdomen & 38 & 78.95 & 21.05 \\
\hline Dysmenorrhea & 4 & 100 & 0 \\
\hline Fever & 2 & 50 & 50 \\
\hline Amenorrhea & 1 & 100 & 0 \\
\hline Bodyache & 4 & 100 & 0 \\
\hline Infertility & 13 & 61.54 & 38.46 \\
\hline Irregular periods & 13 & 69.23 & 30.77 \\
\hline Itching & 16 & 75 & 25 \\
\hline Backache & 15 & 53.33 & 13.64 \\
\hline Menorrhagia & 2 & 100 & 0 \\
\hline
\end{tabular}

*One woman may have more than one complaint

Table 4: HPV serotypes in total study population (110 women).

\begin{tabular}{|llll|}
\hline Serotype & $\begin{array}{l}\text { As single serotype } \\
\mathbf{N}(\%)\end{array}$ & $\begin{array}{l}\text { In combination with } \\
\text { other serotypes }(\%)\end{array}$ & Total $(\%)$ \\
\hline $\mathbf{1 6}$ & $11(10)$ & $4(3.63)$ & $15(13.63)$ \\
\hline $\mathbf{1 8}$ & $3(2.72)$ & $1(0.91)$ & $4(3.63)$ \\
\hline $\mathbf{3 1}$ & 0 & $2(1.81)$ & $2(1.81)$ \\
\hline $\mathbf{3 3}$ & $2(1.81)$ & $1(0.91)$ & $3(2.72)$ \\
\hline $\mathbf{3 9}$ & $1(0.90)$ & $1(0.91)$ & $2(1.81)$ \\
\hline $\mathbf{5 2}$ & $1(0.91)$ & $1(0.91)$ & $2(1.81)$ \\
\hline $\mathbf{5 6}$ & $1(0.91)$ & 0 & $1(0.91)$ \\
\hline $\mathbf{6 6}$ & $1(0.91)$ & 0 & $1(0.91)$ \\
\hline
\end{tabular}

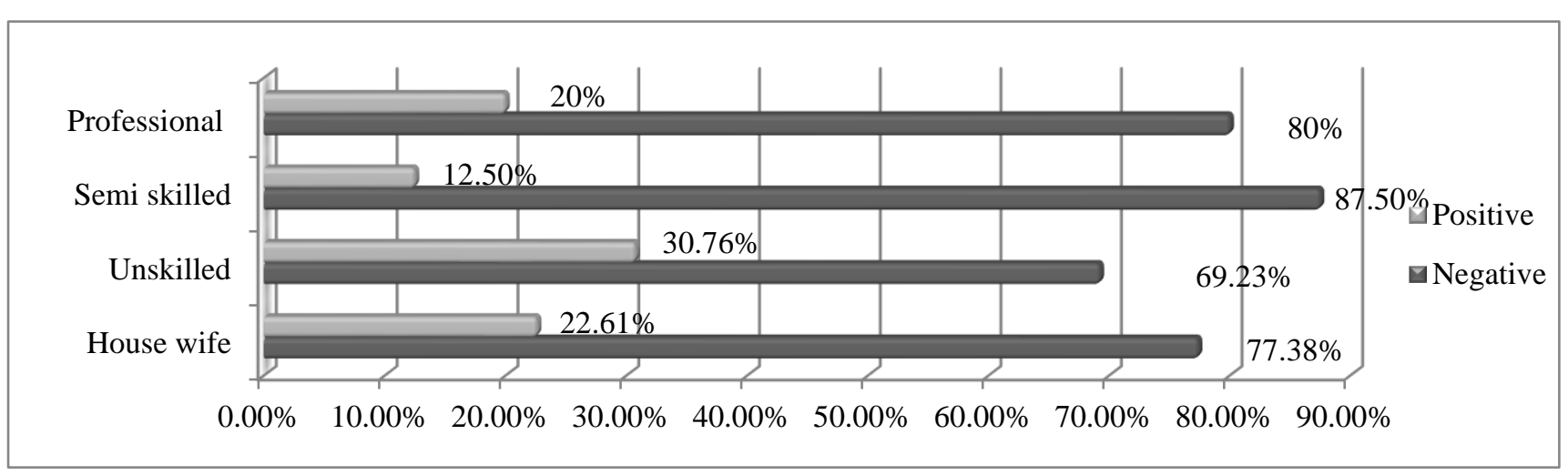

Figure 1: Distribution of women by their occupation and HPV status.

$\mathrm{Y}$ axis shows the occupation and $\mathrm{X}$ axis denotes the percentage of women with their HPV status in relation to occupation 


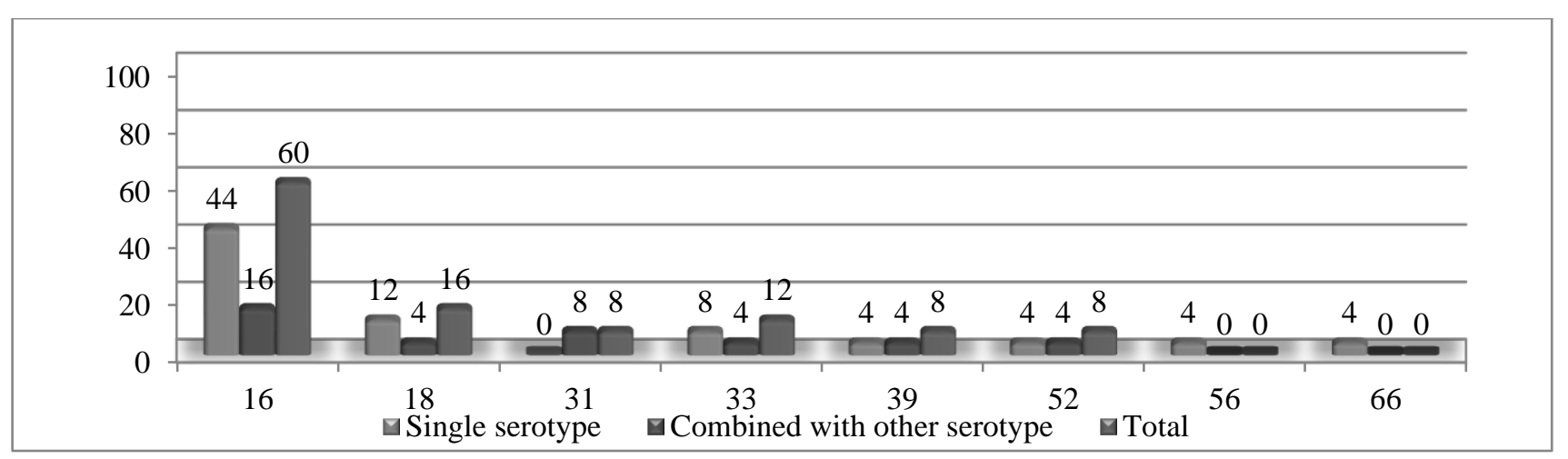

Figure 2: Distribution of HPV serotypes in 25 positive women.

\section{DISCUSSION}

The prevalence of HPV infection in our study population was $22.73 \%$. A study conducted at two apex referral hospitals in Odisha with a mix of urban and rural population reported a prevalence of $60.33 \%$. However, one of these hospitals was a regional cancer center and therefore had a greater number of women with cervical malignancies. ${ }^{9}$ An urban study based in Delhi NCR, the capital of India reported a prevalence of $68.6 \%$ overall. ${ }^{10}$ Another study in rural Maharashtra used menstrual pads to screen for HPV infection in menstruating mothers (age 3050 years) and their daughters (age 12 to 18 years). ${ }^{11}$ They reported a positivity rate of $4.3 \%$ in the older women and $10.7 \%$ in the younger ones. Sowjanya et al reported a $10.3 \%$ prevalence in community-based screening in samples collected by clinicians. ${ }^{12}$ In a meta-analysis that studied the distribution of HPV in South East Asian women, the prevalence of HPV was reported as $94.6 \% .^{13}$ This variability in prevalence may be attributed to difference in the study designs as well as method of samples collected for analysis. Most of the studies focus on urban population and more research is needed to determine the prevalence in rural population.

An interesting finding was presence of HPV in women with infertility and irregular periods (Table 3 ). $38.46 \%$ of HPV positive women had infertility as a presenting complaint. This was not statistically different from women that did not report infertility. Amongst the positive women, $20 \%$ had infertility. A meta-analysis of eleven studies evaluating the association of HPV positivity and female infertility noted a significant association between high-risk HPV and female infertility. ${ }^{14}$

Another finding in our study was the absence of relation of HPV to socio economic status of women. Many studies report a significant association between low socioeconomic levels and HPV infection..$^{9,10,15}$ The difference may be attributed to the criteria used to define the socioeconomic strata. While we used the standard Kuppuswamy scale other studies classified them as low or high income, or low, middle and high groups.
Education was also inversely related to HPV. Women with lower education levels were significantly positive for HPV in our overall model. Aggarwal et al reported a significant higher rate of high-risk HPV in illiterate women or those that were educated for less than six years. ${ }^{15}$ Another study on women in rural India, reported an inverse association of HPV positivity in women with high school education versus those with no education. ${ }^{16}$ Senapati et al did not report a difference in women with no education versus those that were educated. ${ }^{9}$ However the criteria or duration of education was not clear in this study.

Type 16 was the commonest found in $10 \%$ women in isolation and $13.63 \%$ in combination with other types. This was in accordance with other studies. ${ }^{9,13,17}$ The next commonest was type 18. ${ }^{9,12} \mathrm{HPV}$ viruses are classified as low risk and high risk depending upon their association with cervical intraepithelial neoplasia and cancer cervix. Type 16, 18, 31, 45, 33, 35, 39, 51, 52, 56, 58, 66, 68, and 70 are associated with cervical cancer. The metaplastic activity at the squamo- columnar junction, the target for HPV associated transformation is greatest at puberty and after first pregnancy and tends to decline after menopause. The high-risk HPV viruses lead to a persistent infection and hence are oncogenic. ${ }^{18}$

In our study, even though the overall prevalence of HPV was not very high but the predominant types were 16 and 18 which are implicated in malignancy. Type 16 and 18 together accounted for $76 \%$ of all HPV types detected indicating the magnitude of prevalence of these high risk subtypes in this group of women.

\section{CONCLUSION}

Our study indicates that HPV prevalence in young Indian women is high and the 'high risk' types are the commonest. These women are at higher risk for developing malignancies. There is an urgent need to focus more on testing for HPV in cervical samples for prevention of cervical cancer in these women. The latent period between initiation of infection and slow progression to cancer underscores the importance of testing and screening at an early age. 


\section{ACKNOWLEDGEMENTS}

Authors would like to thank and appreciate Aarti Kushwaha, research assistant, AIIMS Raipur for her help in compiling the data.

\section{Funding: No funding sources}

Conflict of interest: None declared

Ethical approval: The study was approved by the Institutional Ethics Committee

\section{REFERENCES}

1. Forounzanfar M, Foreman K, Delossantos A, Lozano R, Murray C, Naghavi M. Breast and cervical cancer in 187 countries between 1980 and 2010: a systematic analysis. The Lancet. 2011;378(9801):1461-84.

2. Sarma U, Mahanta J, Borkakoty B, Sarmah B. Distribution of human papilloma virus infections of uterine cervix among women of reproductive age--a cross sectional hospital-based study from North East India. Asian Pacific J Canc Prev. 2015;16(4):1519-23.

3. Schiffman M, Bauer H, Hoover R, Glass A, Cadell D, Rush B, et al. Epidemiologic evidence showing that human papillomavirus infection causes most cervical intraepithelial neoplasia. J Natl Cancer Inst. 1993;85:958-64.

4. Bosch F, Lorincz A, Munoz N, Meijer C, Shah K. The causal relation between human papillomavirus and cervical cancer. J Clin Pathol. 2002;55:244-65.

5. Damasus-Awatai G, Freeman-Wang T. Human papilloma virus and cervical screening. Curr Opin Obstet Gynecol. 2003;15(6):473-7.

6. Li N, Franceschi S, Howell-Jones R, Snijders PJ, Clifford GM. Human papillomavirus type distribution in 30,848 invasive cervical cancers worldwide: Variation by geographical region, histological type and year of publication. Int $\mathbf{J}$ Cancer. 2011;128(4):927-35.

7. Ribeiro A, Figueiredo Alves R, Costa M, Villa L, Zeferino L, Mauricette Derchain S, Dos Santos Carneiro M, Rabelo-Santos et al. Association between HPV types and species groups and cervical neoplasia from a high-risk area for cervical cancer, Goiânia, Brazil. Int J Gynecol Pathol. 2011;30(3):288-94.

8. Sharma K, Kathait A, Jain A. Higher prevalence of human papillomavirus infection in adolescent and young adult girls belonging to different Indian tribes with varied socio-sexual lifestyle. PLoS One. 2015;10:e0125693

9. Senapati R, Nayak B, Kar SK, Dwibedi B. HPV Genotypes distribution in Indian women with and without cervical carcinoma: Implication for HPV vaccination program in Odisha, Eastern India. BMC Infect Dis. 2017;17(1):30.

10. Kapoora C, Sharma M. Prevalence of HPV infection in reproductive aged female in Delhi NCR region. Clin Epidemiol Global Health. 2020;8(2):612-5.

11. Budukh A, Maheshwari A, Palayekar V, Bagal S, Purwar P, Deodhar K, Dikshit R, Badwe R. Prevalence and nonsexual transmission of human papilloma virus (HPV) in the adolescence girls from rural area of Maharashtra state, India. Indian J Cancer. 2018;55(4):336-9.

12. Sowjanya A, Jain M, Poli U, Padma S, Das M, Shah $\mathrm{K}$, et al. Prevalence and distribution of high-risk human papilloma virus (HPV) types in invasive squamous cell carcinoma of the cervix and in normal women in Andhra Pradesh, India. BMC Infect Dis. 2005;22(5):116.

13. Bhatla N, Dar L, Rajkumar Patro A, Kumar P, Pati SK, Kriplani A, et al. Human papillomavirus-type distribution in women with and without cervical neoplasia in north India. Int $\mathbf{J}$ Gynecol Pathol. 2008;27(3):426-30.

14. Yuan S, Qiu Y, Xu Y, Wang H. Human papillomavirus infection and female infertility: a systematic review and meta-analysis. Reprod Bio Med Online. 2020;40(2):229-37.

15. Aggarwal R, Gupta S, Nijhawan R, Suri V, Kaur A, Bhasin V, Arora SK. Prevalence of high--risk human papillomavirus infections in women with benign cervical cytology: a hospital based study from North India. Indian J Cancer. 2006;43(3):110-6.

16. Franceschi S, Rajkumar R, Snijders P, Arslan A, Mahé C, Plummer M, Sankaranarayanan R, Cherian J, Meijer C, Weiderpass E. Papillomavirus infection in rural women in southern India. $\mathrm{Br} \mathrm{J}$ Cancer. 2005;92(3):601-6.

17. Sontakke B, Ambulkar P, Talhar S, Shivkumar P, Bharambe M, Pal A. Molecular Genetic Study to Detect Prevalence of High-risk Human Papilloma Virus Strains (type 16 and 18) in Cervical Lesions and Asymptomatic Healthy Subjects of Rural Central India. J Cytol. 2019;36(1):32-7.

18. Burd EM. Human papillomavirus and cervical cancer. Clin Microbiol Rev. 2003;16(1):1-17.

Cite this article as: Bagde MN, Bagde ND, Deshmukh P, Negi S, Thangaraju P. Prevalence and genotype distribution of human papilloma virus in cervical samples of young married women: a hospital based prospective cross-sectional study. Int J Reprod Contracept Obstet Gynecol 2021;10:4113-8. 